\title{
Exposure of chitosan to UV/ozone: Structural information and antibacterial activity
}

\author{
Osiris W. Guirguis ${ }^{1 *}$, Gehan T. El-Bassyouni ${ }^{2}$, Mona A. Esawy ${ }^{3}$, Nada R. Abd Elkader ${ }^{1}$, Hadeer M. Mahmoud ${ }^{1}$, \\ Hend M. Mostafa ${ }^{1}$, Nabawia A. Abdel-Zaher ${ }^{4}$ \\ ${ }^{1}$ Biophysics Department, Faculty of Science, Cairo University, Giza, Egypt. \\ ${ }^{2}$ Ceramic, Refractories and Building Materials Department, National Research Center, Giza, Egypt. \\ ${ }^{3}$ Department of Chemistry of Natural and Microbial Products, National Research Center, Giza, Egypt. \\ ${ }^{4}$ Textile Metrology Lab, National Institute for Standards, Giza, Egypt.
}

\section{ARTICLE INFO \\ Article history: \\ Received on: 01/10/2016 \\ Revised on: 14/11/2016 \\ Accepted on: $26 / 11 / 2016$ \\ Available online: $28 / 12 / 2016$}

\section{Key words:}

Chitosan, Structural

information, FTIR,

Antibacterial activity,

UV/ozone treatment.

\begin{abstract}
In the present work, variation in the group coordination of chitosan due to the exposure to UV/ozone was considered by the FTIR reflectance. Pronounced variations in the intensities of reflectance bands and shifts in their positions were detected. This could be attributed to the change in the molecular configuration of chitosan. On the other hand, the well diffusion method was used to investigate the anti-bactericidal activities against two common bacterial strains [Bacillus subtitles (B. subtilis) and Escherichia coli (E. coli)] by detecting the mean inhibition zone diameters (IZD) against the microorganisms. The achieved data revealed that the chitosan exposed to UV/ozone confirmed a high potential of antibacterial activity.
\end{abstract}

\section{INTRODUCTION}

Chitin is a natural polysaccharide synthesized by a great number of living organisms and functions as a structural polysaccharide. Chitosan is a modified natural carbohydrate polymer of glucosamine and $\mathrm{N}$-acetyl glucosamine derived from chitin by deacetylation (Tolaimate et al., 2000). Chitosan possesses positive ionic charges, which give it the facility to chemically bind with negatively charged fats, lipids, cholesterol, metal ions, proteins, and macromolecules (Li et al., 1992). Chitosan has some advantageous properties, such as biocompatibility, biodegradable polymer of high molecular weight non toxic and antimicrobial activity, that encourage its applications in many fields including agricultural (Rodriguez

* Corresponding Author

Osiris W. Guirguis, Biophysics Department, Faculty of Science,

Cairo University, Postcode: 12613, Giza, Egypt.

Tel.: 00202-01223251345; E-mail: osiris_wgr@yahoo.com et al., 2007, Nguyen Anh Dzung et al., 2011), paper industry, food and textile industries, pharmaceutics (Ouattara et al., 2000, Muzzarelli et al., 2005), biochemistry, biotechnology, cosmetic, and biomedical applications (Li et al., 2005, Alves and Mano 2008, Dzung 2014, Ngo and Kim 2014). Chitosan shows good performance in drug delivery and analgesia (Wang et al., 2002). Despite the enlarged knowledge of microbial pathogenesis and application of modern therapeutics, the morbidity and mortality associated with the microbial infections remain high (Dutta et al., 2010). Bacterial resistance to antibiotics has been addressed by looking for new antibiotics and modified antibiotics. In recent years considerable attention has established the antimicrobial activity of chitin, chitosan and their derivatives against different groups of microorganisms (Khanafari et al., 2008, Dutta et al., 2010, Yang et al., 2010), such as bacteria, yeast, and fungi. The antimicrobial activities of chitosan are greatly reliant on its physical characteristics, molecular weight (MW) and degree of deacetylation (\% DDA). 
Chitosan with a higher degree of deacetylation inclines to have a higher antimicrobial activity (Liu et al., 2001). In addition, higher antimicrobial effect against Escherichia coli is presented by water insoluble chitosan (Acharya et al., 2005). Furthermore, improvement of the antibacterial activity of chitosan by adding Jojoba liquid wax against Staphylococcus aureus and Bacillis subtilis, by using the agar disc diffusion method is previously reported (Osiris et al., 2013).

Many researchers (Chien and Chou 2006), from their obtained results, have declared that the molecular weight is one of the main factors affecting the antibacterial activity of chitosan. Also, chitosan antimicrobial activity of chitosan is dependent on both the chitosan and the microorganism used (Park and Kim 2010).

Ultraviolet (UV) radiation represents a part of a broad spectrum of wavelengths emitted from the sun. The Ozone layer absorbed most UV radiation while some of it gets through to reach the surface of the Earth.UV-radiation has positive and also negative applications. Although the wide spectrum of the advantages of UV is also harmful; any polymers (plastics, nylon, polystyrene, ...etc) used in consumer items are broken down and/or lose strength due to exposure to UV-radiation. In addition, fabrics, furnishings and paintings need protection from UV to prevent color change or loss. Products made of natural polymer such as chitosan for biomedical applications need to be sterilized. For the sterilization of materials made of polymers, both UVradiation and high temperature can be used (Struszcyk 2002, Sionkowska et al., 2014).

Irradiation by ultraviolet, which possesses the energy sufficient to cleavage covalent bonds, results in formation of free radicals which they can initiate further reaction such as degradation and/or recombination reactions (Ramani and Rangananthaiah 2000). On other hand, the photolysis of polymer leads mainly to a random scission of chain backbone. Random homolitic scission of main-chain carbon-carbon bonds and photolysis or photodissociation of side groups are two major degradation reactions can occur. After irradiation, oligomer is formed which is mainly due to chain depolymerization after photolytic scission (Wasikiewicz et al., 2005).

UV-radiation as an accessory factor has been found to be an effective and efficient means for the accelerated degradation of chitosan treated with ozone. Therefore, the behavior of the UVradiation and ozone radiation is important on the development of chitosan in several fields, such as biomedical, cosmetic and industry ones. The structure of the degraded chitosan obtained by ozone treatment combined with ultraviolet radiation is characterized by FTIR (Mao et al., 2004, Wu et al., 2009).

The aim of the present work was to study the variation in the group coordination of chitosan in the FTIR reflectance in the range of 4000-450 $\mathrm{cm}^{-1}$ due to exposure to UV/ozone for three diverse intervals. The well diffusion method was processed in order to investigate the anti-bactericidal activities of chitosan exposed to UV/ozone against two bacterial strains Bacillus subtitles (Gram positive) and Escherichia coli (Gram-negative).

\section{MATERIALS AND METHODS}

\section{Material}

Off-white Shrimp chitosan powder (CAS No: 9012-76-4) with average molecular weight of 900,000 to 1,000,000 Dalton and deacetylation above $90 \%$ and free of E. coli and Salmonella was supplied from Oxford Lab Chem. Mumbai, India.

\section{UV/Ozone Treatment}

Chitosan powder samples were exposed to UV/ozone for three episodes of 55, 110 and 220 minutes. High intensity, lowpressure mercury lamp without outer envelope - LRF 02971, 200 watt, 220 volt, $184.9 \mathrm{~nm}$ (Poland) was used as the UV/ozone source placed in a cubic box of dimensions $60 \times 60 \times 60 \mathrm{~cm}$ at National Institute for Standards, Giza, Egypt (Robert and Francis 1996, Michael et al., 2004). Atomic oxygen is generated both when molecular oxygen is subjected to the $184.9 \mathrm{~nm}$ radiation and when ozone is irradiated at $253.7 \mathrm{~nm}$. The $253.7 \mathrm{~nm}$ radiation is absorbed by most hydrocarbons and also by ozone. The samples are placed around the source at a distance $20 \mathrm{~cm}$.

\section{Fourier Transform Infrared (FTIR)}

The FTIR spectra of both the unexposed and the exposed chitosan samples were achieved using potassium bromide $(\mathrm{KBr})$ pellet technique (Sankar et al., 2004, Kassai 2009, Smith 2011). Pellets are prepared by mixing $1 \mathrm{mg}$ of the powdered sample with $100 \mathrm{mg}$ of dried $\mathrm{KBr}$ powder. Mixing is carried out using a pestle and agate mortar. The mixture is then pressed using a special die at a pressure of 10,000 pounds per square inch to produce a pellet. The FTIR reflectance spectra were performed over the range of $4000-450 \mathrm{~cm}^{-1}$ at room temperature using a Bruker Vector 22 Spectrophotometer (Germany) with accuracy better than $\pm 1 \%$ and a resolution of $4 \mathrm{~cm}^{-1}$.

\section{Antimicrobial Activity}

The antibacterial activity of the unexposed and exposed chitosan to UV/ozone against two common bacterial strains: Bacillus subtilis ATCC6633 as Gram-positive and Escherichia coli ATCC25922 as Gram-negative, was carried out using the agar well diffusion method (Magaldi et al., 2004, Valgas et al., 2007). The medium is sterilized by autoclaving at $120^{\circ} \mathrm{C}\left(15 \mathrm{lb} / \mathrm{in}^{2}\right)$. About $30 \mathrm{~mL}$ of the agar medium with the respective strains of bacteria is reassigned aseptically into each sterilized Petri plate. The agar plate surface was inoculated with $1 \times 10^{7}$ colony forming unit (CFU) for bacteria. The plates were left at room temperature for solidification. Then, a well with a diameter of 0.6 to $0.8 \mathrm{~cm}$ was punched aseptically using a sterile cork borer (wells are 2.0 $\mathrm{cm}$ apart from one another) and a volume (20-100 mL) of the antimicrobial agent at desired concentration is introduced into the well. Then, agar plates were incubated under suitable conditions at $37 \pm 2^{\circ} \mathrm{C}$ for $24 \mathrm{~h}$ depending upon the test microorganism, under aerobic conditions. After incubation, confluent bacterial growth is detected. The standard disc $0.6 \mathrm{~cm}$ diameter with ciprofloxacin (50 $\mu \mathrm{g} / \mathrm{disc}$ ) is used as control for antibacterial activity. The diameter 
of the inhibition zone was measured around the well (in $\mathrm{cm}$ ) using Vernier caliper. All tests are accomplished under sterile conditions in duplicates and repeated three times for each sample and the average diameter zone of inhibition is calculated.

\section{RESULTS AND DISCUSSION}

\section{Fourier Transform infrared (FTIR) Spectral Analyses}

FTIR spectroscopy is one of the most common characterization methods for chitin and chitosan due its simplicity, relative instrument availability and independence of sample solubility ( $\mathrm{Ng}$ et al., 2006). The FTIR reflectance spectra of chitosan before and after exposure to UV/ozone with frequency range of $4000-450 \mathrm{~cm}^{-1}$ were shown (Fig. 1). The chemical assignments for the unexposed and exposed chitosan were considered (Table 1).

It was noticed that the FTIR spectrum of unexposed chitosan designated the details of functional groups present in correlation with that of earlier reports (Kweon et al., 2001, Zheng et al., 2001, Pawlak and Mucha 2003, Qi et al., 2004, Pranoto et al., 2005, Zvezdova 2010, Hawary et al., 2011, Puvvada et al., 2012, Long 2013, Vimal et al., 2013, Kumari and Kumar-Rath 2014, Arafat et al., 2015) and was comparable to that of the exposed chitosan. The absorption bands of unexposed chitosan were matching to those of standard chitins. Different stretching vibration bands were observed in the range of $3439-2852 \mathrm{~cm}^{-1}$ related to $v(\mathrm{~N}-\mathrm{H})$ in $v\left(\mathrm{NH}_{2}\right)$ associated with primary amines. The band at $3439 \mathrm{~cm}^{-1}$ could be assigned to $v(\mathrm{~N}-\mathrm{H}), v(\mathrm{O}-\mathrm{H})$ and $v$ $\left(\mathrm{NH}_{2}\right)$ which was present in chitosan in diverse amounts among which $\mathrm{NH}_{2}$ groups being the least. The presence of methyl group in $\mathrm{NHCOCH}_{3}$, methylene group in $\mathrm{CH}_{2} \mathrm{OH}$ and methylene group in pyranose ring was evidenced by the corresponding stretching vibrations of these groups in the range of $2921-2852 \mathrm{~cm}^{-1}$. The band at $1593 \mathrm{~cm}^{-1}$ had a higher intensity than that of $1659 \mathrm{~cm}^{-1}$, which proposes effective degree of deacetylation. When chitin deacetylation happened, the band observed at $1659 \mathrm{~cm}^{-1}$ decreased, while a growth of another band at $1593 \mathrm{~cm}^{-1}$ occurred, designating the prevalence of $\mathrm{NH}_{2}$ groups. When the same spectrum of chitosan after exposure to UV/ozone was observed, the band from $1500-1700 \mathrm{~cm}^{-1}$ was stressed, designating an intensification of the peak around $1593 \mathrm{~cm}^{-1}$ while, a reduction around $1659 \mathrm{~cm}^{-1}$. These observations indicated the degree of deacetylation (DDA) (Zvezdova 2010, Kumari and Kumar-Rath 2014).

The FTIR results showed that, there was a noticeable variation in the intensities of the reflectance bands and shifts in the band positions. This could be attributed to the change in the molecular configuration of chitosan that occurred due to the exposure to UV/ozone. In addition, the observed change in the spectral position of some bands after exposure to UV/ozone could be accredited to some of the sensitive monomer units of chitosan.

Using the FTIR spectrum attained, accurate DDA could be calculated using the Baxter, Dillon et al. formula (Baxter et al., 1992):

$$
\% \mathrm{DDA}=100-\left[\left(\mathrm{A}_{1655} / \mathrm{A}_{3450}\right) \times 115\right]
$$

$\mathrm{A}_{1655}$ and $\mathrm{A}_{3450}$ were the absorptions bands at a wavelength of 1655 and $3450 \mathrm{~cm}^{-1}$, respectively. The induced change in the degree of deacetylation (\%DDA) of the unexposed and exposed chitosan to UV/ozone for various exposure times were determined by FTIR and their percentage changes were revealed in Table 2.

Table 1: Positions and assignments of unexposed and exposed chitosan to UV/ozone.

\begin{tabular}{|c|c|c|c|c|}
\hline \multicolumn{4}{|c|}{ Wavenumber $\left(\mathrm{cm}^{-1}\right)$} & \multirow[b]{2}{*}{ Chemical assignments } \\
\hline $\begin{array}{c}\text { Un- } \\
\text { exposed }\end{array}$ & $\begin{array}{c}55 \text { minutes } \\
\text { exposure }\end{array}$ & $\begin{array}{l}110 \text { minutes } \\
\text { exposure }\end{array}$ & $\begin{array}{l}220 \text { minutes } \\
\text { exposure }\end{array}$ & \\
\hline 3439 & 3435 & 3454 & 3444 & $\begin{array}{l}\text { Combined peaks of the } \mathrm{NH}_{2} \text { and } \mathrm{OH} \text { group stretching vibration Water soluble chitosan } \\
\text { stretching peak }\end{array}$ \\
\hline 2921 & 2923 & 2925 & 2924 & Symmetric $\mathrm{CH}_{3}$ stretching and asymmetric $\mathrm{CH}_{2}$ stretching \\
\hline 2852 & 2852 & 2859 shoulder & 2859 shoulder & $\mathrm{C}-\mathrm{H}$ stretching vibration \\
\hline 1659 & 1658 & 1658 & 1662 & $\mathrm{CONH}_{2}$ group Amide I band Water soluble chitosan stretching peak \\
\hline 1642 & 1641 & 1641 & 1643 & $\mathrm{C}-\mathrm{O}$ and $\mathrm{N}-\mathrm{H}$ stretching, amide I water soluble chitosan stretching peak \\
\hline 1627 & 1631 & 1631 & 1627 & $-\mathrm{NH}_{2}$ amide II Bending vibration of $\mathrm{NH}$ from $\mathrm{R}-\mathrm{NH}_{2}$ \\
\hline 1593 & 1599 & 1606 & 1592 & $-\mathrm{NH}_{2}$ bending (amide II ) \\
\hline 1563 & 1552 & 1552 & 1552 & $\mathrm{~N}-\mathrm{H}$ stretching (amide II) \\
\hline 1537 & 1536 & 1536 & 1536 & $\mathrm{~N}-\mathrm{H}$ bending \\
\hline 1462 & 1462 & 1462 & 1462 & $-\mathrm{NH}_{2},-\mathrm{NH}$ Bend \\
\hline 1422 & 1427 & 1422 & 1423 & $\mathrm{CH}_{2}$ bending and $\mathrm{CH}_{3}$ deformation $\mathrm{C}-\mathrm{N}-$ stretching (amide $\mathrm{II}$ ) \\
\hline 1384 & 1382 & 1383 & 1384 & $\mathrm{CH}_{3}$ in amide group, $-\mathrm{C}-\mathrm{O}$ stretching of primary alcoholic group $\left(-\mathrm{CH}_{2}-\mathrm{OH}\right)$ \\
\hline 1335 & 1335 & 1335 & 1324 & $\mathrm{C}-\mathrm{N}$ stretch (amide III) \\
\hline 1251 & 1268 & 1252 & 1252 & $\mathrm{C}-\mathrm{N}$, free amino group \\
\hline 1165 & 1154 & 1162 & 1156 & Asymmetric stretching of the $\mathrm{C}-\mathrm{O}-\mathrm{C}$ bridge \\
\hline 1098 & 1092 & 1089 & 1079 & C-O stretching vibration Water soluble chitosan stretching peak \\
\hline 1035 & 1035 & 1039 & 1035 shoulder & $\mathrm{C}-\mathrm{O}$ stretching \\
\hline 896 & 898 & 896 & 897 & C-O stretching of glycoside linkage N-H (amide III) Ring stretching \\
\hline
\end{tabular}


Table 2: Variation in the $\%$ degree of deacetylation (\% DDA) of unexposed and exposed chitosan to UV/ozone by FTIR and their percentage exchange $\% \Delta$ (\%DDA).

$\begin{array}{ccc}\text { Chitosan samples } & \text { \%DDA } & \text { \%0(\%DDA) } \\ \text { Unexposed } & 37.49 & - \\ 55 \text { minutes exposure } & 51.21 & 36.6 \% \\ 110 \text { minutes exposure } & 53.39 & 42.4 \% \\ 220 \text { minutes exposure } & 43.79 & 16.8 \%\end{array}$

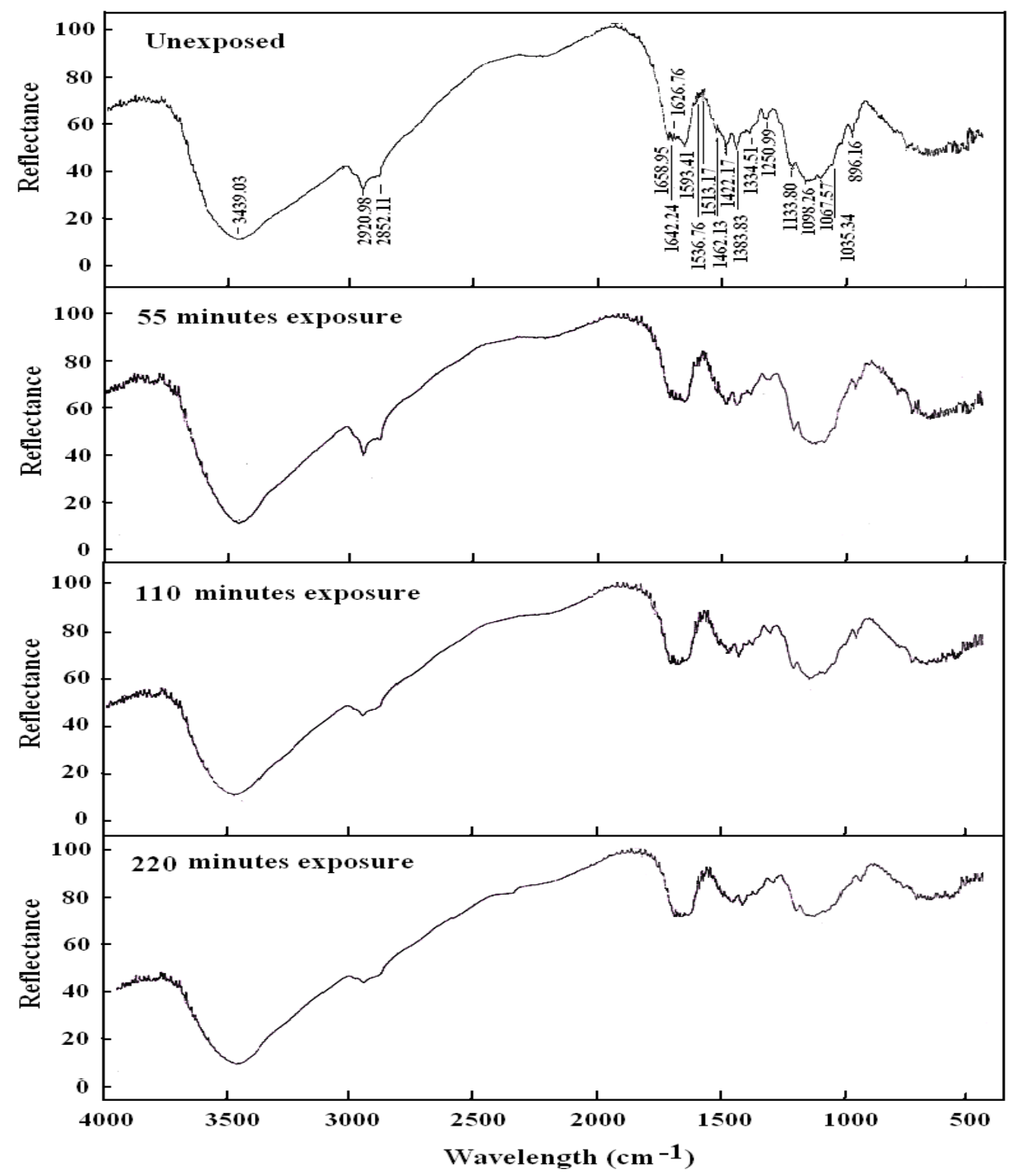

Fig. 1: Variations in FTIR spectra of unexposed and exposed chitosan to UV/ozone.

\section{Antibacterial Activity}

The antibacterial activities of unexposed and exposed chitosan were experienced against two common bacterial strains: Bacillus subtilis (ATCC6633) as Gram-positive and Escherichia coli (ATCC25922) as Gram-negative. The antibacterial activity was articulated as inhibition zone diameters (IZD) measured in $\mathrm{cm}$ of samples against the pathological strains based on the well diffusion assay. The effect of exposure to UV/ozone for 55 minutes (as an example) on: B. subtilus (a) and $E$. coli (b) bacteria were shown (Fig. 2). The average, standard deviation and their percentage changes in inhibition zone diameters for unexposed and exposed chitosan were interpreted in Table 3 . The results revealed that the inhibition zones diameters upsurge upon exposing to UV/ozone in both Gram positive and Gram negative bacteria. In addition, the results testified that the highest inhibition zone was achieved with chitosan exposed to UV/ozone for 55 minutes with very high significant inhibitions against $B$. subtilis and $E$. coli. Furthermore, the data emphasized that the exposure of chitosan to UV/ozone validated a high potential for enlightening the antibacterial activity. This coincides with the findings of Pranoto et al. (2005) who concluded that the antibacterial effect of chitosan occurred without migration of active agents. 

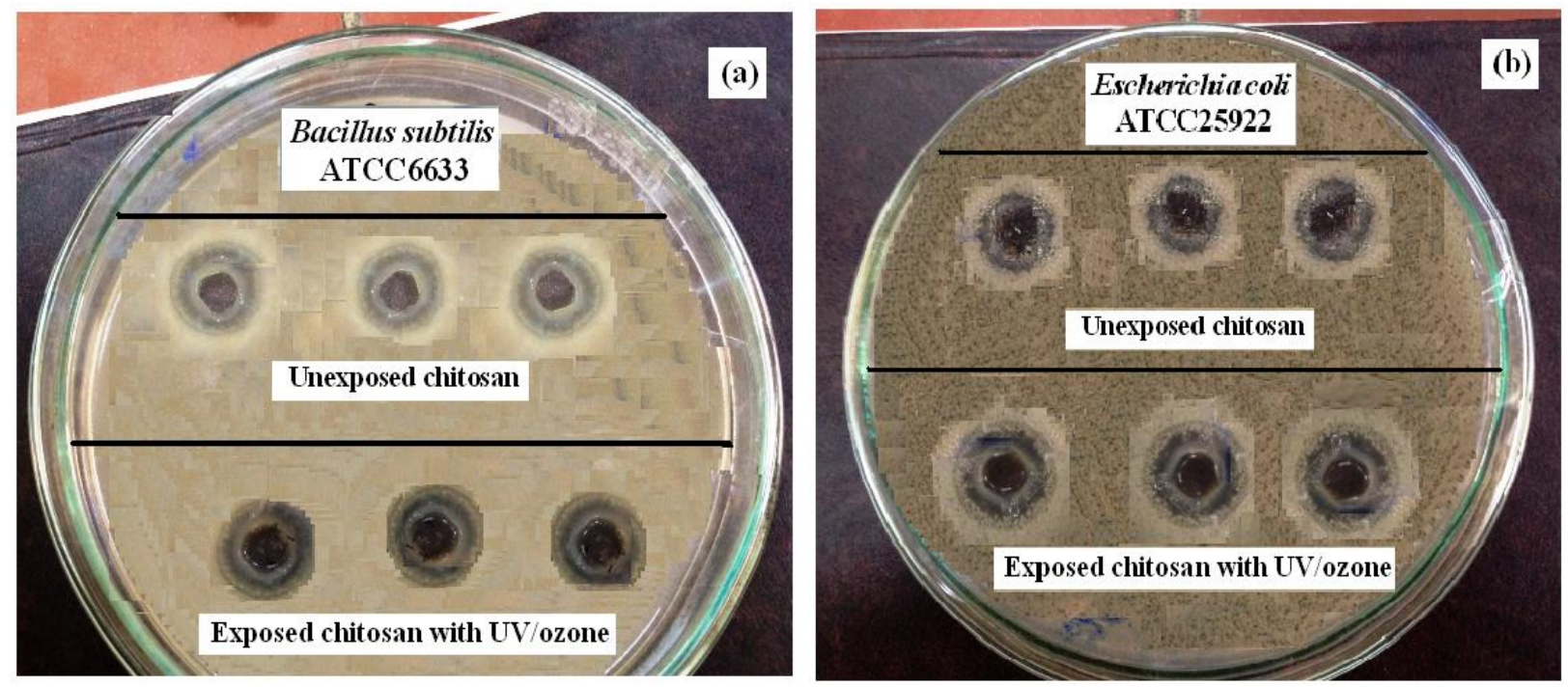

Fig. 2: Effect of exposure to UV/ozone for 55 minutes on: B. subtilus (a) and E. coli (b) bacteria.

Table 3: Average, standard deviations and their percentage variations of the inhibition zone diameters of chitosan against the microorganisms Bacillus subtilis and Escherichia coli. Cibrofloxacin $(50 \mu \mathrm{g})$ used as standard for antibacterial activity.

\begin{tabular}{|c|c|c|}
\hline Chitosan samples & Bacillus subtilis (cm) & Escherichia coli $(\mathbf{c m})$ \\
\hline Unexposed & $1.533 \pm 0.047$ & $1.367 \pm 0.047$ \\
\hline 55 minutes exposure & $\begin{array}{c}2.000 \pm 0.010 \\
30.46 \% \\
\mathrm{P}<0.001 \text { (vhs) }\end{array}$ & $\begin{array}{c}1.700 \pm 0.082 \\
24.4 \% \\
\mathrm{P}<0.001 \text { (vhs) }\end{array}$ \\
\hline 110 minutes exposure & $\begin{array}{c}1.667 \pm 0.047 \\
8.7 \% \\
\mathrm{P}<0.05(\mathrm{~s}) \\
\end{array}$ & $\begin{array}{c}1.533 \pm 0.047 \\
12.1 \% \\
\mathrm{P}<0.01(\mathrm{hs})\end{array}$ \\
\hline 220 minutes exposure & $\begin{aligned} & 1.550 \pm 0.047 \\
& 1.1 \% \\
& \mathrm{P}> 0.05(\mathrm{~ns}) \\
&\end{aligned}$ & $\begin{array}{c}1.467 \pm 0.047 \\
7.3 \% \\
\mathrm{P}<0.05(\mathrm{~s}) \\
\end{array}$ \\
\hline Ciprofloxacin $(50 \mu \mathrm{g})$ & $2.10 \pm 0.071$ & $2.30 \pm 0.020$ \\
\hline
\end{tabular}

On other hand, several studies approved that an increase in the positive charge of chitosan binds it into the bacterial cell walls more intensely (Liu et al., 2006). Therefore, chitosan exposed to UV/ozone improves its antibacterial efficacy. Moreover, diffused antibacterial activity of chitosan, motivated the clearing zone of the bacterial growth. In addition, the cause of the inhibition of microbial cells by chitosan exposed to UV/ozone upsurges the interaction with anionic groups on the cell surface, due to its poly-cationic nature. This may motivate the formation of an impermeable layer around the cell, which prevents the conveyance of necessary solutes (Kamala et al., 2013).

From the obtained data, better efficacy by 55 minutes exposure to UV/ozone instead of the other two longer exposures (110 and 220 minutes) was observed. This may arise from the variation in the total number available states caused by UV/ozone according to the compromise between the degradation and crosslinking processes due to UV/ozone exposure (Chikwenze and Nnabuchi 2010, Abd El-Kader et al., 2010). Also, this better efficacy may be attributed to the change of the molecular configuration by exposure with UV/ozone which leads to rupture of the bonds and formation of free radicals as a result of the degradation process. On other hand, by increasing the time of UV/ozone exposure up to 220 minutes, the cross-linking process was more pronounced and then, the obtained change may be due to the structural changes in the chitosan matrix. This means that both degradation and cross-linking processes were existed due to UV/ozone exposure and the degradation process was more pronounced at shorter exposure while cross-linking process was more significant at longer exposure time.

\section{CONCLUSIONS}

The present study delineated that the FTIR results pronounced variations in the intensities of the reflectance bands and shifts in their positions were detected. This could be attributed to changes in the molecular configuration of chitosan due to the exposure to UV/ozone.

In addition, the achieved data highlighted that the chitosan exposed to UV/ozone gained a prospective antibacterial activity. Furthermore, chitosan degradation by ozone treatment combined with ultraviolet radiation is a very promising technique that can be applied successfully. 


\section{ACKNOWLEDGEMENTS}

This work was carried out through the collaboration between Biophysics Department, Faculty of Science, Cairo University; National Research Center (NRC) and National Institute for Standards, Egypt.

\section{Financial support and sponsorship: Nil}

Conflict of Interests: There are no conflicts of interest.

\section{REFERENCES}

Abd El-Kader FH, Gafer SA, Basha AF, Bannan SI, Basha MAF. Thermal and optical properties of gelatin/poly(vinyl alcohol) blends. Journal of Applied Polymer Science, 2010; 118: 413-420.

Acharya B, Kumar V, Varadaraj MC, Lalitha R, Rudrapatnam $\mathrm{N}$. Characterization of chito-oligosaccharides prepared by chitosanolysis with the aid of papain and pronase, and their bactericidal action against Bacillus cereus and E. coli. Biochemical Journal, 2005; 391: 167-175.

Alves MN, Mano JF. Chitosan derivatives obtained by chemical modifications for biomedical and environmental applications. International Journal of Biological Macromolecules, 2008; 43: 401-414.

Arafat A, Samad SA, Masum SMd, Moniruzzaman M. Preparation and characterization of chitosan from shrimp shell waste. International Journal of Scientific \& Engineering Research, 2015; 6: 538541.

Baxter A, Dillon M, Anthony Taylor KD, Roberts GAF. Improved method for IR determination of the degree of $\mathrm{N}$-acetylation of chitosan. International Journal of Biological Macromolecules, 1992; 14: 166-169.

Chien P, Chou C. Antifungal activity of chitosan and its application to control post-harvest quality and fungal rotting of Tankan citrus fruit (Citrus tankan Hayata). Journal of the Science of Food and Agriculture, 2006; 86: 1964-1969.

Chikwenze RA, Nnabuchi MN. Effect of deposition medium on the optical and solid state properties of chemical bath deposited CdSe thin films. Chalcogenide Letters, 2010; 7: 389-396.

Dutta PK, Tripathi S, Mehrotra GK, Dutta J. Perspectives for chitosan based antimicrobial films in food applications. Food Chemistry, 2009; 114: 1173-82

Dzung NA. 2014. Chitosan and chitosan derivatives as potential adjuvants for influenza vaccine. In: Chitin and Chitosan Derivatives: Advances in Drug and Discovery and Developments, Publisher: CRC Taylors \& Francis, Editors: Se Kwon Kim.

Hawary DL, Motaleb MA, Farag H, Guirguis OW, Elsabee MZ. Lactosaminated N-succinyl-chitosan as a liver-targeted carrier of ${ }^{99 \mathrm{~m}} \mathrm{Tc}$ in vivo for nuclear imaging and biodistribution. Journal of Labelled Compounds and Radiopharmaceuticals, 2011; 54: 664-670.

Kamala K, Sivaperumal P, Rajaram R. Extraction and characterization of water soluble chitosan from Parapeneopsis stylifera shrimp shell waste and its antibacterial activity. International Journal of Scientific and Research Publications, 2013; 3: 1-8.

Kassai MR. Various methods for determination of the degree of $\mathrm{N}$-acetylation of chitin and chitosan: A review. Journal of Agricultural and Food Chemistry, 2009; 57: 1667-1676.

Khanafari A, Marandi R, Sanatei Sh. Recovery of chitin and chitosan from shrimp waste by chemical and microbial methods. Iranian Journal of Environmental Health Science and Engineering, 2008; 5: 19-24.

Kumari S, Kumar-Rath P. Extraction and characterization of chitin and chitosan from (Labeo rohit) fish scales. Procedia Materials Science, 2014; 6: 482-489.

Kweon HY, Um LC, Park YH. Structural and thermal characteristics of antheraeapernyi silk fibroin/chitosan blend film. Polymer, 2001; 42: 6651-6656.

Li Q, Dunn ET, Grandmaison EW, Goosen MFA. Applications and properties of chitosan. Journal of Bioactive and Compatible Polymers, 1992; 7: 370-397.
Li Z, Ramay HR, Hauch KD, Xiao D, Zhang M. Chitosanalginate hybrid scaffolds for bone tissue engineering. Biomaterials, 2005; 26: 3919-3928.

Liu N, Chen X-G, Park HJ, Liu CG, Meng X-H, Yu LJ. Effect of $\mathrm{Mv}$ and concentration of chitosan on antibacterial activity of Escherichia coli. Carbohydrate Polymers, 2006; 64: 60-65.

Liu X, Yun L, Dong Z, Zhi L, Kang D. Antibacterial action of chitosan and carboxymethylated chitosan. Journal of Applied Polymers Science, 2001; 79: 1324-1335.

Long JHWS. 2013. Synthesis and characterization of chitosan from shrimp shells. A Project Report Submitted in Partial Fulfillment of the Requirements for the Award of Bachelor of Engineering (Hons.). Materials and Manufacturing Engineering, Faculty of Engineering and Science, Universiti Tunku Abdul Rahman, Malaysia.

Magaldi S, Mata-Essayag S, Hartung de Capriles C, Perez C, Colella MT, Olaizola C, Ontiveros Y. Well diffusion for antifungal susceptibility testing. International Journal of Infectious Diseases, 2004; 8 : $39-45$.

Mao S, Shuai X, Unger F, Simon M, Bi D, Kissel T. The depolymerization of chitosan: Effects on physicochemical and biological properties. International Journal of pharmaceutics, 2004; 281: 45-54.

Michael MN, El-Zaher NA, Ibrahim SF. Investigation into surface modification of some polymeric fabrics by UV/ozone treatment Polymer-Plastics Technology and Engineering, 2004; 43: 1041-1052.

Muzzarelli RAA, Muzzarelli C. Chitosan chemistry: Relevance to the biomedical sciences. Advances in Polymer Science Journal, 2005; 186: $151-209$

$\mathrm{Ng} \mathrm{CH}$, Hein CS, Stevens WF. The mechanical and biological properties of chitosan scaffolds for tissue regeneration templates are significantly enhanced by chitosan from Gongronella butleri. Journal of Biomedical Materials Research Part B: Applied Biomaterials, 2006; 76 : 155-160.

Ngo DN, Kim SK. Antioxidant, antimicrobial properties of chitin, chitosan, and their derivatives. Advances in Food and Nutrition Research, 2014; 73: 15-31.

Nguyen Anh Dzung, Vo Thi Phuong Khanh, Tran Trung Dzung. Research on impact of chitosan oligomers on biophysical characteristics, growth, development and drought resistance of coffee Carbohydrate Polymers, 2011; 84: 751-755.

Osiris WG, Abd Elkader MFH, Nasrat AA. Enhancing antimicrobial activity for chitosan by adding Jojoba liquid wax. Materials Letters, 2013; 93: 353-355.

Ouattara B, Simard RE, Piette G, Begin A, Holley RA Inhibition of surface spoilage bacteria in processed meats by application of antimicrobial films prepared with chitosan. International Journal of Food Microbiology, 2000; 62: 139-148.

Park BK, Kim MM. Applications of chitin and its derivatives in biological medicine. International Journal of Molecular Science, 2010; 11 : 5152-5164.

Pawlak A, Mucha M. Thermogravimetric and FTIR studies of chitosan blends. Thermochimica Acta, 2003; 396: 153-166.

Pranoto Y, Rakshit SK, Salokhe VM. Enhancing antimicrobial activity of chitosan films by incorporating garlic oil, potassium sorbate and nisin. LWT - Food Science and Technology, 2005; 38: 859-865.

Puvvada YS, Vankayalapati S, Sukhavasi S. Extraction of chitin from chitosan from exoskeleton of shrimp for application in the pharmaceutical industry. International Current Pharmaceutical Journal, 2012; 1: 258-263.

Qi L, Xu Z, Jiang X, Hu C, Zou X. Preparation and antibacterial activity of chitosan nanoparticles. Carbohydrate Research, 2004; 339: 2693-2700.

Ramani R, Rangananthaiah C. Degradation of acrylonitrilebutadiene-styrene and polycarbonate by UV Irradiation. Polymer Degradation and Stability, 2000; 69: 347-354.

Robert MS, Francis XW. 1996. Spectrometric identification of organic compounds. Sixth Edition, Vol. 27, No. 12.

Rodriguez AT, Ramirez MA, Cardenas RM, Hernandez AN, Velazquez MG, Bautista S. Induction of defense response of Oryza sativa L. against Pyricularia grisea (Cooke) Sacc. by treating seeds with chitosan 
and hydrolyzed chitosan. Pesticide Biochemistry and Physiology, 2007; 89: 206-215.

Sankar V, Suresh Kumar T, Panduranga Rao K. Preparation, characterization and fabrication of intracellular lens from photo initiated polymerised poly(methyl methacrylate). Trends in Biomaterials \& Artificial Organs, 2004; 17: 24-30.

Sionkowska A, Planecka A, Lewandowska K, Michalska M. The Influence of UV-Irradiation on thermal and mechanical properties of chitosan and silk fibroin mixture. J Photochem Photobiol B, 2014; 140: 301-305.

Smith BC. Fundamentals of Fourier transform infrared spectroscopy. Second Edition, CRC Press, Boca Raton, London, New York, 2011.

Struszcyk MH. Chitin and chitosan. Part II: Applications of chitosan. Polimery, 2002; 47: 396-403.

Tolaimate A, Desbrières J, Rhazi M, Alagui M, Vincendon M, Vottero P. The influence of deacetylation process on the physicochemical characteristics of chitosan from squid chitin. Polymer, 2000; 41: $2463-$ 2469.

Valgas C., De Souza SM, Smânia EFA. Screening methods to determine antibacterial activity of natural products. Brazilian Journal of Microbiology, 2007; 38: 369-380.

Vimal S, Abdul Majeed S, Taju G, Nambi KSN, Sundar Raj N, Madan N, Farook MA, Rajkumar T, Gopinath D, Sahul Hameed AS. Chitosan tripolyphosphate (CS/TPP) nanoparticles: Preparation, characterization and application for gene delivery in shrimp. Acta Tropica, 2013; 128: 486-493.

Wang L, Khor E, Wee A, Lim LY. In: Chitosan-alginate PEC membrane as a wound dressing: Assessment of incisional wound healing. Journal of Biomedical Materials Research, 2002; 63: 610-618.
Wasikiewicz JM, Yoshii F, Nagasawa N, Wach RA, Mitomo H. Degradation of chitosan and sonochemical and ultraviolet methods. Radiation Physics Chemistry, 2005; 73: 287-295.

Wu Y, Rian H, Pingjia Y, Yuanan W. Ultraviolet radiation induced accelerated degradation of chitosan by ozone treatment. Carbohydrate Polymer, 2009; 77: 639-642.

Yang EJ, Kim JG, Kim JY, Kim S, Lee N. Anti-inflammatory effect of chitosan oligosaccharides in RAW 264.7 cells. Central European Journal of Biology, 2010; 5: 95-102.

Zheng H, Du YM, Yu JH, Huang RH, Zhang LN. Preparation and charecterization of chitson/polyvinyl alcohol blend fibres. Journal of Applied Polymer Science, 2001; 80: 2558-2565.

Zvezdova D. Synthesis and Characterization of Chitosan from Marine Source in Black Sea. Proceedings of the Annual Conference, vol. 49 of Series 9.1 - Chemical Technologies, "Angel Kanchev" University of Ruse, 2010, pp. 65-69.

\section{How to cite this article:}

Guirguis OW, El-Bassyouni GT, Esawy MA, Elkader NRA, Mahmoud HM, Mostafa HM, Abdel-Zaher NA., Exposure of chitosan to UV/ozone: Structural information and antibacterial activity. J App Pharm Sci, 2016; 6 (12): 124-130. 